\title{
Mean Platelet Volume and the Ratio of Mean Platelet Volume/Platelet Count in Acute Rheumatic Fever
}

\author{
(1) Dolunay Gürses¹, (1) Funda Akpınar2, (1) Mustafa Doğan33 \\ 1Pamukkale University Faculty of Medicine, Department of Pediatric Cardiology, Denizli, Turkey \\ ${ }^{2}$ Ankara University Faculty of Medicine, Department of Developmental and Behavioral Pediatrics, Ankara, Turkey \\ ${ }^{3}$ Avcılar Hospital, Clinic of Child Health and Diseases, İstanbul, Turkey
}

\begin{abstract}
Aim: Acute rheumatic fever (ARF) is an endemic disease especially in developing countries. Due to an autoimmune response to group B streptococcus throat infection, ARF develops in susceptible children. Mean platelet volume (MPV) reflects the platelet size and the rate of platelet production. It is important in cardiovascular events and rheumatic diseases. The MPV/platelet count ratio was determined to be more sensitive than MPV alone in patients with hepatocellular carcinoma, deep vein thrombosis and myocardial infarction. The aim of this study was to investigate changes in MPV and the MPV/platelet count ratio during the active and remission periods of ARF compared with healthy subjects.

Materials and Methods: This study population consisted with 70 ARF patients and 70 age and gender matched healthy controls. In all subjects, complete blood count; including haemoglobin, white blood cell count (WBC), platelet count, MPV and C-reactive protein (CRP), and erythrocyte sedimentation rate (ESR) were measured during the active stage and during the remission period and compared with healthy individuals.

Results: There was no statistically significant difference between the ARF and control groups in terms of the sex and age ( $>>0.05)$. Forty-one patients in the ARF group had carditis. The ARF patients in the active stage had significantly higher WBC, CRP and ESR values $(p<0.05)$. Although no significant difference was observed in MPV between the groups ( $p>0.05$ ); the MPV/platelet count ratio was low during the active stage but increased during the remission period and reached the same values as the healthy controls $(p<0.001)$.

Conclusion: We did not find any relationship between MPV and ARF. However, a decreased MPV/platelet count ratio was detected during the active stage of ARF. The present findings emphasize the association between the MPV/platelet count ratio and ARF. The MPV/platelet count ratio may be used to determine the activity of ARF.
\end{abstract}

Keywords: Acute rheumatic fever, mean platelet volume, platelet count

\section{Introduction}

Acute rheumatic fever (ARF) results from an autoimmune response to group B streptococcus throat infection in genetically susceptible children (1). The most important complication of ARF is valvular insufficiency, known as rheumatic heart disease. Worldwide, it is the leading cause of cardiovascular death during the first five decades of life (2). In our country, the incidence of rheumatic heart disease has been found to be 8.9/100,000 (3).

In recent studies, mean platelet volume (MPV), which indicates platelet size (4), has been determined to be important in cardiovascular events, and in rheumatic 
diseases like familial Mediterranean fever, Behçet's disease, inflammatory bowel disease, and rheumatoid arthritis (5-11). In the literature, although there are a few studies showing the ARF and MPV association, (12-16) these studies do not put forward any conclusive results indicating the relationship between ARF and MPV. Additionally, in some studies that were done with patients who had hepatocellular carcinoma, deep vein thrombosis and non-ST elevation myocardial infarction, the MPV/platelet ratio was determined to be more sensitive than MPV alone (17-19).

In this study, our aim is to investigate MPV and the $\mathrm{MPV} /$ platelet count ratio in ARF during the acute phase and after treatment and to compare these results with healthy controls.

\section{Materials and Methods}

\section{Study Population}

The study was conducted in the Paediatric Cardiology Department of Pamukkale University. Seventy patients who were hospitalized with a diagnosis of ARF during the acute stage of the disease and an aged matched control group of patients who were diagnosed with innocent murmurs were included in this study. The clinical and laboratory data of the patients were collected retrospectively from hospital records. Although modified Jones criteria were introduced in 2015 , our patients were diagnosed according to older criteria (20). The patients' complete blood count; including white blood cell count (WBC), MPV, platelet count, C-reactive protein (CRP), erythrocyte sedimentation rate (ESR) during the acute stage and after eight weeks of treatment, and during remission were collected. Each patient was evaluated via echocardiographic examination and carditis was diagnosed when pathological valve regurgitation was detected.

All patients underwent 2D, M-mode and colour flow Doppler study using GE Vingmed Vivid 7 model echocardiography (GE Vingmed Ultrasound AS, Horten, Norway) and multi frequency transducer $(2.5-4 \mathrm{~Hz})$ images were taken with the children in the left lateral decubitus position. The patients did not receive sedation during these examinations. Pathological valve regurgitation and normal echocardiographic examination was differentiated by the criteria of the World Health Organization Expert Committee (2004), (21).

Those patients with chronic disease, using medication, or those having abnormal liver or renal function tests were excluded from the study. Forty-one patients of the seventy ARF patients had arthritis (34 of them had mild- moderate carditis and the remaining seven had severe carditis). Salicylate was given to the arthritis and mild carditis patients at $80-100 \mathrm{mg} / \mathrm{kg} /$ day (maximum dose was $3.5 \mathrm{~g} /$ day) and prednisolone was given to the moderate and severe carditis patients at $2 \mathrm{mg} / \mathrm{kg} /$ day (maximum dose was $60 \mathrm{mg} /$ day). This was tapered after two weeks treatment and salicylates was initiated as the prednisolone dosage decreased.

CRP levels $>0.5 \mathrm{mg} / \mathrm{dL}$ and ESR $>20$ /hour were considered as increased.

The Ethical Committee of our institution approved the study (with approval number: 60116787/020/28852 on 16/08/2013).

\section{Statistical Analysis}

All statistical analysis was performed using Sytat statistical software (version 17.0 for windows; SPSS Inc, Chicago, IL, USA). Data were tested for homogeneity of variance with Shapiro-Wilk test. Student's t-test, $x^{2}$ test and One-Way ANOVA were used for data analyses. Statistical significance was taken at $p<0.05$. All data are presented as mean and standard deviation.

\section{Results}

The study was performed on 70 patients (39 males and 31 females) diagnosed with ARF and 70 healthy subjects (39 males and 31 females) as a control group. The mean age of the ARF patients and healthy subjects were 10.8 \pm 3.1 and $11.1 \pm 3.5$ years (range between 5-17 years) respectively. There was no significant difference between the groups in terms of their mean age and $\operatorname{sex}(p>0.05)$. Forty-one of the seventy (59\%) ARF patients had carditis. All patients with carditis had mitral valve involvement. Additionally, in 15 of these patients, there was both mitral and aortic valve involvement (37\%). Four of them (1.9\%) had heart failure.

In patients during the active stage of ARF, CRP and ESR were significantly higher than for the ARF patients who were in remission $(p<0.001)$. Mean CRP and ESR levels were $6.7 \pm 5.4 \mathrm{mg} / \mathrm{dL}$ and $61 \pm 28 \mathrm{~mm} / \mathrm{h}$ respectively during the active stage of ARF and $0.36 \pm 0.25 \mathrm{mg} / \mathrm{dL}$ and $16.6 \pm 8 \mathrm{~mm} / \mathrm{h}$ respectively in ARF patients who were in remission.

Those ARF patients who were in the active stage had significantly higher WBC count than both the control group and the ARF patients who were in the remission period $(p<0.001)$. WBC values reduced to levels close to the control group values during remission $(p>0.05)$ There was no significant difference between the groups for haemoglobin and platelet counts ( $p>0.05)$, (Table I). 
In terms of MPV, although there was no significant difference between the ARF patients in the acute stage and those in remission; the MPV/platelet ratio was significantly lower in the ARF patients in the acute stage than for the healthy control subjects and for the ARF patients in remission $(p<0.05)$. However, the decreased MPV/platelet count ratio in the active stage increased during the remission period and reached the same values as the healthy controls $(p<0.001)$, (Table I).

There was no significant difference between ARF patients with or without carditis in terms of WBC, CRP, ESR, MPV, platelet count or the MPV/platelet ratio $(p>0.05)$ (Table II).

\section{Discussion}

Rheumatic fever is caused by gram-positive bacteria Streptococcus pyogenes and follows untreated throat infections in susceptible children. It also depends on other environmental factors, such as poor living standards and poor access to medical care (20). It results from an autoimmune response to infection of Streptococcus pyogenes. The most important complication of this disease is rheumatic heart disease. While the mean incidence of ARF is $19 / 100,000$ in school-aged children worldwide (22), it was found to be $8.9 / 100,000$ in Turkey (3). The pathogenesis of rheumatic heart disease is complex and involves genetic factors that predispose a person to the development of autoimmune reactions (1).

Platelets are cytoplasmic fragments of megakaryocytes. MPV indicates platelet production and activation and is commonly used as a measure of platelet size (4). The morphology of platelets remains fairly constant during their lifespan. In other words, the regulation of platelet function and aging is primarily aimed at maintaining platelet mass (platelet count multiplied by MPV) and persistent haemostatic potential. It has been put forward that the inverse relationship between platelet count and MPV in physiological and some pathological conditions reflect the tendency to maintain haemostasis by preserving a constant platelet mass (23).

In a recent review about MPV and its clinical use for diagnostic/prognostic purposes of non-haematological diseases, it was emphasized that there is inter individual

Table I. Differences between the patients with ARF during the active stage and in remission compared with the control group

\begin{tabular}{|c|c|c|c|c|c|c|}
\hline & \multirow{2}{*}{$\begin{array}{l}\text { ARF in active stage } \\
(n=70)\end{array}$} & \multirow{2}{*}{$\begin{array}{l}\text { ARF in remission } \\
(n=70)\end{array}$} & \multirow{2}{*}{$\begin{array}{l}\text { Control } \\
(n=70)\end{array}$} & \multicolumn{3}{|c|}{ p-value } \\
\hline & & & & $\mathbf{p}^{*}$ & $\mathbf{p}^{* *}$ & $\mathbf{p}^{* * *}$ \\
\hline Haemoglobin (g/dL) & $12.1 \pm 1.4$ & $12.8 \pm 0.9$ & $13.3 \pm 0.8$ & NS & NS & NS \\
\hline WBC $\left(\mathrm{mm}^{3}\right)$ & $9,319 \pm 3,201$ & $7,668 \pm 2,197$ & $7,334 \pm 1,660$ & $<0.001$ & NS & $<0.001$ \\
\hline Platelet count $\left(\mathrm{mm}^{3}\right)$ & $385,900 \pm 105021$ & $337,914 \pm 87434$ & $286,600 \pm 57,300$ & $<0.001$ & 0,001 & $<0.05$ \\
\hline MPV (fL) & $8.1 \pm 1.4$ & $8.2 \pm 1.5$ & $7.8 \pm 0.8$ & NS & NS & NS \\
\hline MPV/platelet count & $0.022 \pm 0.008$ & $0.026 \pm 0.01$ & $0.028 \pm 0.006$ & $<0.001$ & NS & $<0.05$ \\
\hline \multicolumn{7}{|c|}{$\begin{array}{l}p^{*} \text { : Between ARF patients during the active stage and the control group. } \\
p^{* *}: \text { Between ARF patients in remission and the control group. } \\
p^{* * *} \text { Between patients during the active stage of ARF and ARF patients in remission. } \\
\text { ARF: Acute rheumatic fever, WBC: White blood cell, MPV: Mean platelet volume, NS: Not significance }\end{array}$} \\
\hline
\end{tabular}

Table II. WBC, CRP, ESR, MPV, platelet count and MPV/platelet ratio in ARF patients with or without carditis

\begin{tabular}{|c|c|c|}
\hline & $\begin{array}{l}\text { ARF arthritis } \\
(n=29)\end{array}$ & $\begin{array}{l}\text { ARF carditis } \\
(n=41)\end{array}$ \\
\hline WBC (K/uL) & $9,255 \pm 4,029$ & $9,365 \pm 2,512$ \\
\hline CRP (mg/dL) & $4.5 \pm 5.9$ & $5.1 \pm 5.3$ \\
\hline $\operatorname{ESR}(\mathrm{mm} / \mathrm{h})$ & $56.6 \pm 26.0$ & $63.3 \pm 28.8$ \\
\hline MPV (fL) & $7.8 \pm 1.4$ & $8.3 \pm 1.4$ \\
\hline Platelet count ( $\left.\times 10^{9} / \mathrm{L}\right)$ & $372,241 \pm 106,369$ & $395,560 \pm 104,282$ \\
\hline MPV/platelet ratio (fL/(10 $\left.10^{9} / \mathrm{L}\right)$ & $0.023 \pm 0.008$ & $0.02 \pm 0.008$ \\
\hline
\end{tabular}


variability in healthy subjects and its inverse correlation with platelet count (24). However, in some studies, it was found that there is a relationship between MPV increase and some cardiovascular events and mortality rate $(5,6)$. This is also true for rheumatologic diseases like familial Mediterranean fever (7), Behçet's disease $(8,9)$, inflammatory bowel disease (10) and rheumatic arthritis (11). It was found that there is converse relationship between MPV and disease activity. Although there is an inverse relationship between MPV and rheumatological disease activity in some studies, in rheumatoid arthritis patients, MPV was found to be increased in comparison with a control group (12). In Sert et al.'s (12) study which included 40 ARF patients, (8 had carditis, 32 arthritis) it was reported that MPV was decreased during the acute phase and it increased after treatment in patients with ARF. The authors claimed that in ARF, inflammatory cytokines such as IL-1 and IL- 6 affect megakaryopoiesis and this causes the increase in platelet number and decrease in MPV values (12). However, Ozdemir et al. (13) reported that they did not find any relationship between MPV and rheumatic carditis in a study including 53 patients with rheumatic carditis. Karpuz et al. (15) investigated whole blood parameters of children with rheumatic valvular heart disease and they found elevated MPV levels compared with healthy controls. Also, in Çelik and Çelik (16) study, they found elevation of MPV in patients with valvular regurgitation. Contrary to these studies, our study includes patients with ARF both during the active stages and remission periods, and we did not find any relationship between MPV and ARF either in arthritis or in carditis.

Even though there are contradictory results for MPV and inflammatory diseases, it was found that the MPV/ platelet count ratio was more sensitive than MPV alone in hepatocellular carcinoma (17), deep vein thrombosis (18) and non-ST elevation acute myocardial infarction (19). Also, we found a statistically significant relationship between the MPV/platelet ratio and the acute phase of ARF. This could be explained by increased megakaryopoiesis in inflammatory diseases but, both platelet count and MPV value must be considered.

The strength of our study is the evaluation of MPV, MPV/ platelet ratio, CRP and ESR both during the acute phase and the remission phase of ARF.

\section{Study Limitations}

In our study, there were some limitations. Firstly, our sample size was small for the analysis of MPV and the MPV/ platelet count ratio with the subgroups of the major signs of ARF. Secondly, due to the retrospective design of our study, we did not evaluate the long-term prognosis of our patients.

In the literature, this is the first study investigating the MPV/platelet ratio and ARF during the acute phase and after remission.

\section{Conclusion}

Rather than MPV, the MPV/platelet ratio can be used as inflammatory marker in ARF. However, prospective studies with a larger number of patients are needed to evaluate the efficacy of the MPV/platelet ratio.

\section{Ethics}

Ethics Committee Approval: The Ethical Committee of our institution approved the study (with approval number: $60116787 / 020 / 28852$ on 16/08/2013).

Informed Consent: Retrospective study.

Peer-review: Internally and externally peer-reviewed.

\section{Authorship Contributions}

Design: D.G., Data Collection or Processing: F.A., Analysis or Interpretation: M.D., Writing: F.A.

Conflict of Interest: No conflict of interest was declared by the authors.

Financial Disclosure: The authors declared that this study received no financial support.

\section{References}

1. Guilherme L, Kalil J. Rheumatic fever and rheumatic heart disease: cellular mechanisms leading autoimmune reactivity and disease. I Clin Immunol 2010; 30:17-23.

2. Carapetis IR, Mc Donald M, Wilson N. Acute rheumatic fever. Lancet 2005; 366:155-66.

3. Gürses D. Türkiye'de akut romatizmal ateş neredeyiz? Turkish Pediatric Cardiology and Cardiac Surgery Association, Annual Meeting of Acquired Heart Disease and Prevention Working Group March 2017; AÜTF/Ankara https://turkpedkar.org.tr/tr/ turkiyede-ara-neredeyiz-dolunay-gurses/.

4. Park Y, Schoene N, Harris W. Mean platelet volume as an indicator of platelet activation: methodological issues. Platelets 2002; 13:301-6.

5. Chu SC, Becker RC, Berger PB, et al. Mean platelet volume as a predictor of cardiovascular risk: a systematic review and metaanalysis. I Thromb Haemost 2010; 8:148-56.

6. Akgul $\mathrm{O}$, Uyarel $\mathrm{H}$, Pusurooglu $\mathrm{H}$, et al. Prognostic value of elevated mean platelet volume in patients undergoing primary angioplasty for ST-elevation myocardial infarction. Acta Cardiol 2013; 68:307-14.

7. Makay B, Türkyilmaz Z, Unsal E. Mean platelet volume in children with familial Mediterranean fever. Clin Rheumatol 2009; 28:975-8. 
8. Karabudak O., Nalbant S, Sahan B, Unal M, Ersanli D. Mean platelet volume in Behçet's disease. Akt Rheumatol 2008; 33:217-20.

9. Acikgoz N, Karincaoglu Y, Ermis N, et al. Increased mean platelet volume in Behçet's disease with thrombotic tendency. Tohoku I Exp Med 2010; 221:119-23.

10. Kapsoritakis AN, Koukourakis MI, Sfiridaki A, et al. Mean platelet volume: a useful marker of inflammatory bowel disease activity. Am J Gastroenterol 2001; 96:776-81.

11. Gasparyan AY, Stavropoulos-Kalinoglou A, Toms TE, Douglas $K M$, Kitas GD. Association of mean platelet volume with hypertension in rheumatoid arthritis. Inflamm Allergy Drug Targets 2010; 9:45-50.

12. Sert A, Aypar E, Odabas D. Mean platelet volume in acute rheumatic fever. Platelets 2013; 24:378-82.

13. Ozdemir R, Karadeniz C, Doksoz O, et al. Are mean platelet volume and platelet distribution width useful parameters in children with Acute Rheumatic Carditis? Pediatr Cardiol 2014; 35:53-6.

14. Ileri $M$, Kanat $S$, Gürsoy $H T$, et al. Increased mean platelet volume in rheumatic mitral stenosis: assessment of clinical and echocardiographic determinants. Kardiol Pol 2015; 73:46-53.

15. Karpuz D, Giray D, Ozyurt A, Bozlu G, Unal S, Hallioglu O. Can whole-blood parameters be used in follow-up of children with rheumatic valvular heart disease? Cardiol Young 2017; 27:764-9.

16. Çelik SF, Çelik E. The neutrophil-to-lymphocyte ratio and mean platelet volume can be associated with severity of valvular involvement in patients with acute rheumatic carditis. Cardiovasc ) Afr 2018; 29:296-300.
17. Cho SY, Yang II, You E, et al. Mean platelet volume/platelet count ratio in hepatocellular carcinoma. Platelets 2013; 24:3757.

18. Han JS, Park TS, Cho SY, Joh JH, Ahn HJ. Increased mean platelet volume and mean platelet volume/platelet count ratio in Korean patients with deep vein thrombosis. Platelets 2013; 24:590-3.

19. Azab B, Torbey E, Singh J, et al. Mean platelet volume/platelet count ratio as a predictor of long-term mortality after non-STelevation myocardial infarction. Platelets 2011; 22:557-66.

20. Gewitz M, Baltimore R, Tani L, et al. Revision of the jones criteria for the diagnosis of acute rheumatic fever in the era of doppler echocardiography: a scientific statement from the American Heart Association. Circulation. 2015; 131:1806-18.

21. Rheumatic fever and rheumatic heart disease: Report of a WHO expert consultation (2004) WHO expert consultation on rheumatic fever and rheumatic heart disease, 2001 October 29- November 1, Geneva, Switzerland. WHO Technical Report Series. World Health Organ Tech Rep Ser 923:1-122.

22. Tibazarwa KB, Volmink JA, Mayosi BM. Incidence of acute rheumatic fever in the world: a systematic review of populationbased studies. Heart 2008; 94:1534.

23. Gasparyan AY, Ayvazyan L, Mikhailidis DP, Kitas GD. Mean platelet volume: A link between thrombosis and inflammation? Curr Pharm Des 2011; 17:47-58.

24. Noris $\mathrm{P}$, Melazzini F, Balduini $\mathrm{CL}$. New roles for mean platelet volume measurement in the clinical practice? Platelets 2016; 27:607-12. 